\title{
RENDIMENTO E COMPOSIÇÃO QUÍMICA DO FILÉ DE PROCHILODUS LINEATUS DO RIO MOGI GUAÇU, BRASIL
}

\author{
PROCESSING YIELD AND CHEMICAL COMPOSITION OF THE \\ PROCHILODUS LINEATUS FROM MOGI GUAÇU RIVER, BRAZIL
}

\begin{abstract}
Machado, M.R.F. ${ }^{1}$ e F. Foresti ${ }^{2}$
${ }^{1}$ Centro de Aqüicultura. Universidade Estadual Paulista (CAUNESP). Via de Acesso Prof. Paulo Donato Castelane, s/n. CEP 14887-900. Jaboticabal. São Paulo. Brasil. marcia@zootecnista.com.br ${ }^{2}$ Departamento de Morfologia. Instituto de Biociências. UNESP/Botucatu. São Paulo. Brasil. fforesti@ibb.unesp.br
\end{abstract}

\section{PALAVRAS CHAVE ADICIONAIS}

Composição corporal. Filetagem. Processamento de peixe.

\section{RESUMO}

O curimbatá constitui espécie de peixe de ampla distribuição na região Neotropical e de elevado valor econômico. O objetivo deste trabalho foi comparar o rendimento e a composição química do filé de machos e fêmeas em estoques migradores e residentes de Prochilodus lineatus. Utilizou-se o delineamento experimental inteiramente casualizado em esquema fatorial $4 \times 2$, tendo como fatores quatro estoques (um residente e três migradores) e dois sexos (macho e fêmea) com trinta repetições, considerando cada peixe como unidade amostral. Cada indivíduo foi submetido à filetagem manual e determinação da composição corporal (teores de umidade, proteína bruta, lipídios, cinzas e energia). Foram avaliados os seguintes parâmetros: rendimento do peixe inteiro eviscerado (RPIE \%); rendimento de filé sem osso (RFILE \%) e rendimento de filé com osso (RFILEC \%). Houve diferença significativa $(p<0,05)$ entre os estoques e amostras estudados. Os maiores rendimentos de filé sem osso foram observados para os peixes do estoque migrador I (45,77\%). Machos e fêmeas do estoque migrador I apresentaram maiores rendimentos de filé $(46,79 \%$ e $43,93 \%$, respectivamente), enquanto que o migrador III apresentou menor rendimento $37,29 \%$ para machos e $38,44 \%$ para fêmeas). Os estoques migradores I, II e III apresentaram valores significativamente menores $(p<0,05)$ do nível de lipídios $(0,98 \% ; 2,01 \%$ e $1,97 \%$, respectivamente) e aumento no conteúdo

Recibido: 3-10-07. Aceptado: 1-4-08.

\author{
AdDitional KEYWORdS \\ Corporal composition. Filleted. Processing of fish.
}

de proteína corporal em relação ao estoque residente. Conclui-se que os machos pesando em média $591 \mathrm{~g}$, pertencentes ao estoque migrador I (capturados em dezembro), apresentaram melhores rendimentos de filetagem e os estoques migradores são peixes que tem baixo teor de gordura e alto teor de proteína.

\section{SUMMARY}

The curimbata constitutes species of fish of wide distribution in the Neotropical area and high economic value. This work focused to evaluate processing yield and the chemical composition of the fillet in the male and female migratories and residents stocks of Prochilodus lineatus. The using the plotting was completely randomized by $4 \times 2$ factorial scheme, having as factors four stocks (one resident and three migratories) and two genders (male and female) with thirty replicates, considering each fish as an experimental unit. Each individual was submitted to the manual filleted and determination of the corporal composition (texts of moisture, crude protein, lipids, ashes and energy). They following parameters of yield had been evaluated (\%): visceral entire fish (RPIE \%); yield of boneless fillet (RFILE \%) and processing yield of fillet with bone (RFILEC \%). There was a significant difference $(p<0.05)$ between the stocks and the studied

Arch. Zootec. 58 (224): 663-670. 2009. 
samples. The biggest yield of boneless fillet were observed for the fish of the migrator stock I $(45.77 \%)$. Males and females of the migrator stock I presented biggest fillet yield $(46.79 \%$ and $43.93 \%$, respectively), while the migrator III presented smaller yield $(37.29 \%$ for males and $38.44 \%$ for females). The migratories stocks I, II and III presented values significantly smaller $(p<0.05)$ of lipids level $(0.98 \% ; 2.01 \%$ and $1.97 \%$, respectively) and an increase in the content of corporal protein in relation to the resident stock. It concluded that the male weighing $591 \mathrm{~g}$ on average, belonging of the stock migrator I (captured in December), presented better thread yield and the stocks migratories are fish that has low fat tenor and high protein tenor.

\section{INTRODUÇÃO}

O produto de maior interesse econômico e culinário na atividade pesqueira é a carne, sobre a qual há poucos estudos, para a maioria das espécies, relacionados à sua composição química e ao seu rendimento. Os dados ligados à sua composição são importantes no processo de conservação e elaboração do produto, enquanto que os dados referentes ao rendimento identificam a quantidade comestível e de nutrientes que compõe o filé. A partir da quantificação do rendimento, o produtor poderá planejar a quantidade de peixes necessários para o abate. Dessa forma, a morfologia do peixe, traduzida na proporção de filé, é a primeira impressão do consumidor diante do produto (Wille et al., 2002). Além de ser um fenótipo relacionado ao rendimento de filé, o formato do peixe faz parte dos critérios de escolha dos consumidores de produtos pesqueiros.

$\mathrm{O}$ valor nutritivo e os preços dos peixes dependem da textura e composição química de sua carne, do rendimento e de fatores relacionados as técnicas de captura, beneficiamento e origem do pescado. Segundo Souza et al. (1999), os estudos de carcaça de peixes têm grande importância econômica e de produção, pois, através destes, estimar a produtividade, tanto para o piscicultor como para a indústria de processamento. Embora seja extremamente importante a qualidade nutricional do pescado, também se torna necessário verificar o rendimento de filé, que é um produto pronto para a industrialização. Segundo Macedo-Viegas e Scorvo (2000), características como sexo, tamanho ou idade do peixe podem influenciar valores de rendimento no processamento após o abate.

A padronização das técnicas de filetagem e a definição do tamanho economicamente viável dos animais são variáveis que necessitam ser estabelecidos para obtenção de maiores rendimentos de filé. Os peixes do gênero Prochilodus estão entre as espécies de água doces mais abundantes e difundidas nos rios da América do Sul (Sivasundar et al., 2001). Dessa forma, o curimbatá, Prochilodus lineatus, foi a espécie escolhida para este estudo devido às perspectivas para a criação comercial e às limitadas informações sobre suas características corporais e composição química do filé. O presente estudo objetivou comparar as características de rendimento e composição química do filé de machos e fêmeas, de estoques migradores e residentes de curimbatá (Prochilodus lineatus), capturados no Rio Mogi Guaçu, no Estado de São Paulo, Brasil.

\section{MATERIALE MÉTODOS}

O estudo foi desenvolvido na Universidade Estadual Paulista (UNESP), no Laboratório de Tecnologia de Produtos de Origem Animal, do Departamento de Gestão e Tecnologia Agroindustrial, da Faculdade de Ciências Agronômicas, Campus de Botucatu, no Estado de São Paulo, Brasil. Com o apoio técnico e logístico da equipe do Centro de Pesquisa e Gestão de Recursos Pesqueiros Continentais (CEPTA/ ICMbio), foram capturados exemplares de estoque residente em um único período e migradores em diferentes períodos. Em setembro de 2006, foram capturados trinta exemplares de curimbatás Prochilodus 
a)

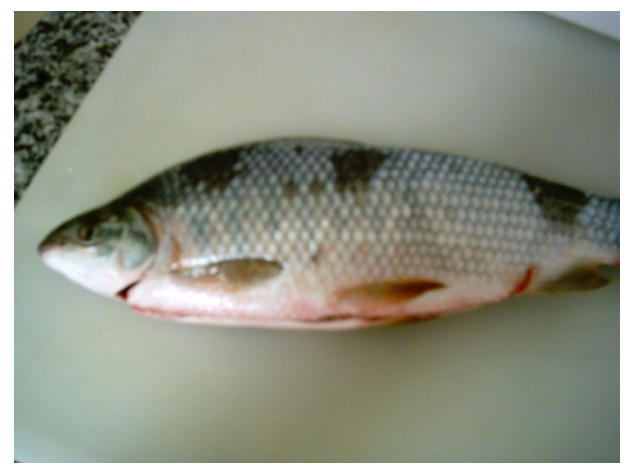

b)

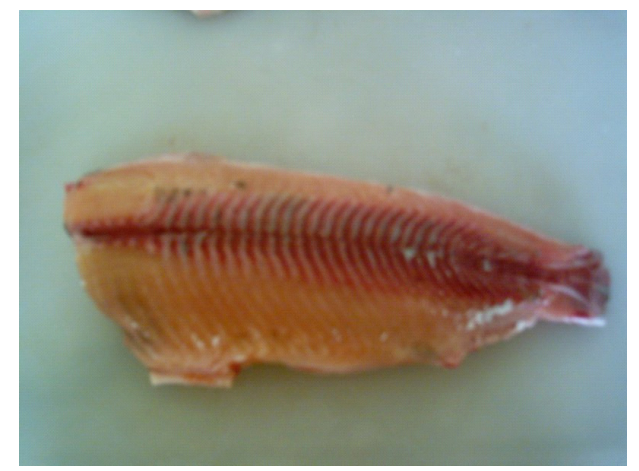

Figura 1. Exemplar de curimbatá, Prochilodus lineatus, utilizados no processamento. a) peixe inteiro eviscerado (PPIE) e b) peixe eviscerado sem cabeça, sem pele e sem nadadeiras (PPISC). (Unit of curimbatá, Prochilodus lineatus, used in the processing. a) the entire fish eviscerated (PPIE) and b) fish eviscerated without head, skin and fin (PPISC)).

lineatus (Valenciennes, 1836) do estoque residente em Cachoeira de Emas (no Rio Mogi Guaçu, Pirassununga, São Paulo, $21^{\circ}$ 92' S e $47^{\circ} 36^{\prime} \mathrm{W}$ ), ou seja, estoque que permanece estacionado neste local durante o ano todo, sem migração. Nos meses de dezembro de 2006, janeiro e março de 2007, foram capturados somente exemplares de curimbatás do estoque migrador (trinta indivíduos de cada mês), provenientes de cardumes que chegam em Cachoeira de Emas $\left(21^{\circ} 93^{\prime} \mathrm{S} \mathrm{e} 47^{\circ} 37^{\prime} \mathrm{W}\right)$ no período da piracema. Os peixes capturados foram mantidos em tanques de terra por 24 horas para depuração e posteriormente foram eutanasiados por

a)

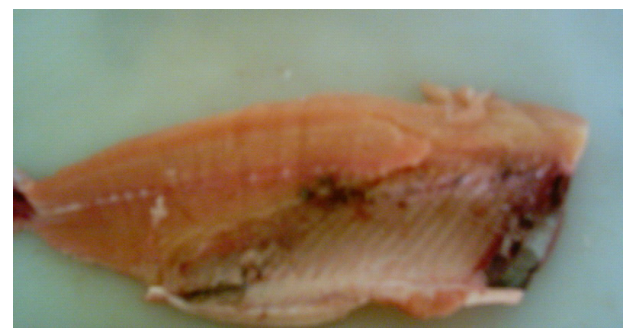

tratamento térmico em água com gelo, seguido do rompimento da coluna cervical. Foram pesados, medidos, eviscerados (manualmente), lavados, embalados individualmente em sacos plásticos, rotulados e transportados no gelo até o laboratório de Tecnologia de Produtos de Origem Animal, na UNESP em Botucatu, onde foram congelados $\left(-20^{\circ} \mathrm{C}\right)$ para posterior análise. Foram realizados os procedimentos para obtenção de dados sobre os pesos de corte (para processamento), de acordo com a metodologia de Carneiro et al. (2003), de cada exemplar (figura 1e 2) foram obtidos os valores de peso do peixe inteiro eviscerado

b)

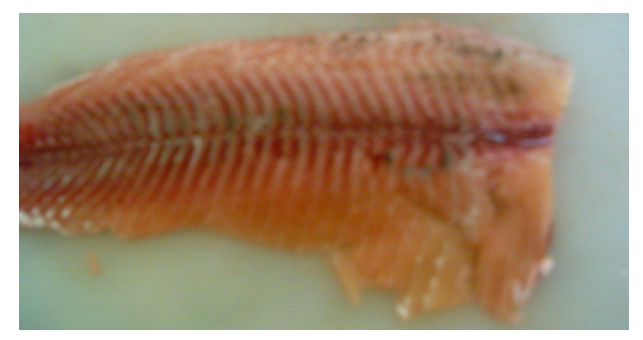

Figura 2. Exemplar de curimbatá, Prochilodus lineatus, após o processamento. a) filé com osso (PFILEC) e b) filé sem osso (PFILE). (Unit of curimbatá, Prochilodus lineatus, after the processing. a) fillet with bone (PFILEC) and b) fillet boneless (PFILE)). 
(PPIE); do peixe eviscerado sem cabeça e sem nadadeiras (PPISC); do filé sem osso (PFILE) e do filé com osso (PFILEC). Os valores de PPIE foram obtidos a partir da abertura ventral da cavidade abdominal desde o orifício urogenital até os ossos da mandíbula, seguida da retirada cuidadosa das vísceras para evitar a contaminação da carne com matéria fecal. A partir do PPIE foi possível a obtenção de outra variável, os peixes foram descongelados, a cabeça, cauda, nadadeiras (anal, peitoral e caudal) e pele foram removidas, resultando no PPISC. O filé foi obtido após a retirada da cabeça e pele do peixe inteiro eviscerado. O corte foi iniciado na região dorsal, lateralmente à nadadeira, desde a região cranial até a extremidade caudal. Os filés foram obtidos inicialmente sem a remoção dos ossos próximos a área ventral (filé com osso), que posteriormente foram retirados, com faca para obtenção do filé sem osso. O rendimento foi obtido por meio dos cortes supracitados, que esta relacionado ao peso inicial do peixe inteiro. Com isso obteve-se os seguintes parâmetros: rendimento do peixe inteiro eviscerado (RPIE \%); rendimento do peixe inteiro eviscerado sem cabeça, nadadeiras e pele (RPISC \%); rendimento de filé sem osso (RFILE \%) e rendimento de filé com osso (RFILEC\%).

Os filés foram posteriormente embalados em sacos plásticos, identificados e congelados $\left(-15^{\circ} \mathrm{C}\right)$ para análises posteriores. A determinação do sexo dos exemplares foi realizada mediante observação direta das gônadas, constatando-se a presença ou não de ovócitos. Todos os procedimentos foram realizados por uma única pessoa, para tentar evitar ou reduzir desvios de análise provocados pelo operador. No momento da realização das análises, as amostras (filés) de cada peixe foram descongeladas parcialmente, trituradas individualmente em multiprocessador até obter-se uma poupa uniforme, alíquotas dessa polpa foram utilizados para a determinação da umidade, por meio de secagem das amostras em estufa a $105^{\circ} \mathrm{C}$, por $16 \mathrm{~h}$, proteína bruta (método de Kjeldahl) utilizando-se o fator 6,25 para conversão do nitrogênio total em proteína bruta, lipídios ou extrato etéreo (método de Soxhlet), cinzas em mufla a $550^{\circ} \mathrm{C}$, até peso constante, e energia por meio de bomba calorimétrica Parr 1281. Todas essas determinações foram feitas segundo a AOAC (2000), os valores obtidos representam a média de três determinações por amostra e os resultados foram expressos em porcentagem $(\%)$.

\section{AnÁliseestatística}

Os resultados obtidos foram submetidos à análise de variância (ANOVA). Utilizouse um delineamento inteiramente casualizado em esquema fatorial $4 \times 2$, sendo quatro tipos de estoques (um residente e três migradores) e dois sexos (macho e fêmea). Quando detectadas diferenças estatisticamente significativas entre os tratamentos, estas foram submetidas ao teste de comparação de médias utilizando-se Tukey, a 5\% de probabilidade, utilizado-se o programa estatístico SAS (2001).

\section{RESULTADOSEDISCUSSÃO}

\section{ReNDIMENTODEFILÉ}

A avaliação de carcaça de peixes tem grande importância econômica e de produção. Com essas informações, pode-se estimar a produtividade, tanto para o piscicultor como para a indústria de processamento de pescado. A parte útil do pescado, também denominada corpo limpo ou tronco limpo (peixe eviscerado), é a parte do corpo pronta para o consumo e/ou a industrialização, sendo que a partir desta pode-se obter o filé.

Na tabela I, constam os valores médios referentes ao peso do peixe inteiro e de rendimentos de filé de diferentes estoques de curimbatá (Prochilodus lineatus). Podese observar diferença significativa $(\mathrm{p}<0,05)$ entre os estoques e as variáveis estudados. O maior rendimento de filé sem osso e com 
Tabela I. Valores médios e intervalos de confiança para peso do peixe inteiro (g) e de rendimentos de filé (\%) do curimbatá (Prochilodus lineatus). (Average and confidence intervals of weight visceral entire fish $(\mathrm{g})$ and processing yield of fillet (\%) the curimbatá (Prochilodus lineatus)).

\begin{tabular}{|c|c|c|c|c|}
\hline Estoque & $\begin{array}{c}\text { Peso do peixe } \\
\text { inteiro }(\mathrm{g})\end{array}$ & filé sem osso & $\begin{array}{l}\text { Rendimento (\%) } \\
\text { filé com osso }\end{array}$ & eviscerado \\
\hline Residente & $934,67 \pm 104,12$ & $42,22 \pm 4,31$ & $56,44 \pm 2,14$ & $85,86 \pm 1,82$ \\
\hline Migrador I & $590,71 \pm 118,39$ & $45,77 \pm 5,09$ & $59,84 \pm 2,89$ & $86,59 \pm 1,85$ \\
\hline Migrador II & $750,67 \pm 111,33$ & $40,66 \pm 4,16$ & $52,40 \pm 1,53$ & $91,38 \pm 1,90$ \\
\hline $\begin{array}{l}\text { Migrador III } \\
\text { Teste F }\end{array}$ & $513,33 \pm 83,78$ & $38,09 \pm 2,51$ & $46,74 \pm 0,94$ & $91,25 \pm 1,11$ \\
\hline Estoque (E) & $15,38^{* *}$ & $16,83^{* *}$ & $30,52^{* *}$ & $15,48^{* *}$ \\
\hline Sexo (S) & $9,97^{* *}$ & $10,83^{* *}$ & $5,52^{* *}$ & $13,11^{* *}$ \\
\hline Interação (E x S) & $0,45^{\text {ns }}$ & $2,73^{* *}$ & $1,67^{\mathrm{ns}}$ & $0,88^{\text {ns }}$ \\
\hline C.V. $(\%)$ & 38,62 & 9,24 & 9,46 & 4,83 \\
\hline
\end{tabular}

${ }^{* *} p<0,05 ;{ }^{n s}$ ão significativo $(p>0,05)$.

osso foi observado para os peixes do estoque migrador I $(45,77 \%$ e $59,84 \%$, respectivamente), quando comparado com os demais. Segundo Contreras-Guzmán(1994), a forma do corpo tem grande importância no processamento do pescado pela indústria, influenciando nas operações de decapitação, evisceração e, inclusive, no rendimento da carne quando processada na forma de corpo limpo, postas ou filés. Segundo esse autor, os peixes fusiformes como o curimbatá apresenta valores de rendimento relativamente altos por apresentarem massa muscular cilíndrica, superando valores de $54 \%$ de rendimento de filé com pele. No presente trabalho, encontrou-se valores acima de $46 \%$ de rendimento de filé com osso e sem pele para Prochilodus lineatus (tabela I), que apresentou valores mais altos que o citado por Contreras-Guzmán (1994).

O rendimento de filé pode variar entre as espécies e dentro da mesma espécie. Segundo Rasmussen e Ostenfeld (2000), o rendimento de filé pode ser influenciado pelo tamanho e pela espécie de peixe. Souza (2001) e Souza et al. (1999) afirmaram que vários fatores influenciam no rendimento após o abate, tais como sexo, tamanho ou idade do peixe, o método de filetagem e a destreza do filetador.

Em relação ao sexo (tabela II), os machos e fêmeas do estoque migrador I apresentaram maiores rendimentos de filé $(46,79 \%$ e $43,93 \%$, respectivamente) enquanto que o migrador III apresentou menor rendimento $(37,29 \%$ e $38,44 \%)$. O maior rendimento do filé nos machos verificado no estoque migrador I, possivelmente ocorreu devido ao fato das fêmeas estarem em pleno desenvolvimento gonadal, em estágio evoluído, coincidindo o período de coleta

Tabela II. Médias do rendimento de filé sem osso de curimbatá (Prochilodus lineatus) considerando os estoques e o sexo. (Averages of the processing yield of fillet boneless of curimbatá (Prochilodus lineatus) considering the stocks and the sex).

\begin{tabular}{|c|c|c|c|c|}
\hline \multirow[t]{2}{*}{ Estoques } & \multirow[t]{2}{*}{ Residente } & \multicolumn{3}{|c|}{ Migrador } \\
\hline & & I & II & III \\
\hline Macho & $43,90^{\mathrm{Ab}}$ & $46,79^{\mathrm{Aa}}$ & $42,16^{\mathrm{Ab}}$ & $37,29^{A c}$ \\
\hline Fêmea & $39,33^{\mathrm{Bb}}$ & $43,93^{\mathrm{Aa}}$ & $38,69^{\mathrm{Bb}}$ & $38,44^{\mathrm{Ab}}$ \\
\hline
\end{tabular}

Médias seguidas da mesma letra na coluna (maiúscula) e linha (minúscula), não diferem entre si pelo teste de Tukey $(p>0,05)$. 


\section{MACHADOEFORESTI}

com a época de reprodução, em relação ao rendimento verificado no estoque migrador III, pode ser explicado por serem peixes mais jovens e de menor tamanho. Contudo, esses valores estão diretamente relacionados a fatores ligados à matéria prima, como a idade ou peso do peixe, estação do ano, sexo, desenvolvimento gonadal, espécie, formato anatômico e tamanho da cabeça.

\section{ANÁLISEDECOMPOSIÇÃOQUIIMICA}

$\mathrm{Na}$ tabela III constam os dados referentes aos valores encontrados de proteína bruta, lipídios, cinzas, umidade e energia do filé de curimbatá nos diferentes estoques. Em geral, o músculo do pescado contém cerca de $60 \%$ a $85 \%$ de umidade, variando com a espécie, época do ano, idade, sexo e estado nutricional (Ogawa, 1999) no entanto o teor de umidade encontrado no filé foi superior $(\mathrm{p}<0,05)$ para o estoque migrador I $(78,51 \%)$ em relação ao estoque residente $(77,33 \%)$; os menores valores foram encontrados para os estoques residentes e migrador III, situando-se na faixa citada por Ogawa (1999). Houve interação dos estoques e os sexos (machos e fêmeas) quanto aos teores de umidade, os teores de cinzas estão dentro da faixa relatada por ContrerasGuzmán(1994), de 0,80\% a 1,4\% para peixes ósseos em geral (tabela III).

A proteína e os lipídios são nutrientes importantes na mobilização e formação de tecido corporal, sendo os principais responsáveis pelo crescimento e ganho de peso nos peixes, dessa forma, os depósitos de lipídio podem ser localizados em diferentes tecidos ou órgãos de acordo com a espécie e idade do peixe e afetam a qualidade da carne (Regost et al., 2001). No presente trabalho observou-se que o teor de lipídios $(3,16 \%)$ e energia $(135,91 \mathrm{kcal} / 100 \mathrm{~g})$ foram superiores $(\mathrm{p}<0,05)$ para o estoque residente em relação aos estoques migradores. Esse aumento era esperado, pois, atingindo determinado peso, geralmente o animal reduz a taxa de crescimento e intensifica a deposição de gordura na carcaça e, conseqüentemente, no filé e pelo fato dos peixes residentes apresentarem hábito estacionário em um lugar, não havendo altos gastos de energia como em processos de longas migrações. Segundo ContrerasGuzmán (1994), tanto a gordura corporal quanto à das gônadas aumentam simultaneamente nos períodos iniciais de desova. Os estoques migradores I, II e III apresentaram valores significativamente menores ( $\mathrm{p}<0,05)$ do nível de lipídios $(0,98 \%, 2,01 \%$ e $1,97 \%$, respectivamente) e aumento no

Tabela III. Valores médios da composição centesimal de filé de curimbatá (Prochilodus lineatus). (Average values of the centesimal composition of fillet of curimbatá (Prochilodus lineatus)).

\begin{tabular}{lccccc}
\hline Estoque & $\begin{array}{c}\text { Umidade } \\
(\%)\end{array}$ & $\begin{array}{c}\text { Cinzas } \\
(\%)\end{array}$ & $\begin{array}{c}\text { PB } \\
(\%)\end{array}$ & $\begin{array}{c}\text { Lipídios } \\
(\%)\end{array}$ & $\begin{array}{c}\text { Energia } \\
(\mathrm{kcal} / 100 \mathrm{~g})\end{array}$ \\
\hline Residente & 77,33 & 1,24 & 18,67 & 3,16 & 135,91 \\
Migrador I & 78,51 & 1,18 & 14,66 & 0,98 & 114,97 \\
Migrador II & 78,04 & 1,28 & 19,66 & 2,01 & 117,66 \\
Migrador III & 77,77 & 1,41 & 18,76 & 1,97 & 115,05 \\
Teste F & & & & & $19,26^{* *}$ \\
Estoque (E) & $38,09^{* *}$ & $46,53^{* *}$ & $80,56^{* *}$ & $11,80^{* *}$ \\
Sexo (S) & $2,81^{\text {ns }}$ & $3,77^{* *}$ & $0,28^{\text {ns }}$ & $0,19^{\text {ns }}$ & $0,63^{\text {ns }}$ \\
Interação (ExS) & $3,24^{\text {ns }}$ & $2,51^{\text {ns }}$ & $0,79^{\text {ns }}$ & $0,51^{\text {ns }}$ & $0,22^{\text {ns }}$ \\
C.V. (\%) & 29,74 & 29,32 & 27,53 & 66,63 & 12,15 \\
\hline
\end{tabular}

${ }^{* *} p<0,05 ;{ }^{n s}$ não significativo $(p>0,05)$. 
conteúdo de proteína corporal em relação ao estoque residente. Tais dados são concordantes com os de Contreras-Guzmán (1994), nos quais os peixes jovens, normalmente os menores da espécie, apresentam menor teor de gordura que os adultos, o fato de se encontrar em fase de crescimento diminui a gordura disponível para reserva. O autor também cita uma tabela descrita por Jacquot (1961), para classificação dos peixes quanto ao teor de gordura, em que os peixes com teores abaixo de $2,5 \%$ de gordura são considerados magros. Silva e Chamul (2000) também classificam os peixes quanto ao teor de gordura, ou seja, peixe gordo $(>10 \%$ de gordura), moderadamente gordo $(5-10 \%)$ e magro $(<5 \%)$. Portanto, pode-se dizer que os estoques migradores de curimbatás se enquadram entre os peixes magros, pois, apresentaram valores de $0,98 \%, 2,01 \%$ e $1,97 \%$ para os estoques migradores I, II e III, respectivamente. A classificação do peixe pelo teor de gordura tem importância, pois pode influenciar diretamente na performance produtiva e na aceitação pelo mercado consumidor, além de alterar a palatabilidade da carne do peixe.

Os valores médios de lipídios e proteínas na maioria das amostras permitem classificar esta espécie na categoria A de Stansby (1954) onde os peixes têm baixo teor de gordura $(<5 \%)$ e alto teor de proteína $(15-20 \%)$.

Os teores de proteínas em relação ao sexo (tabela IV) estão dentro da faixa relatada por Stansby (1954), os machos do estoque migrador II apresentaram maiores teores de proteína $(19,91 \%)$ enquanto que o migrador III apresentou menor teor de proteína $(18,22 \%)$. O teor de proteína, em relação às fêmeas foi maior para o estoque migrador II $(19,41 \%)$ e menor valor para o estoque migrador I (10,90\%). Os peixes migradores, por realizar nado forçado durante a piracema, apresentam uma diminuição do nível de lipídios corporais e aumento no conteúdo de proteína corporal em relação aos estoques residentes. Com relação ao teor de lipídios as médias das amostras dos estoques residentes, migradores I, II e III (3,16\%, $0,98 \%, 2,01 \%$ e $1,97 \%$, respectivamente) encontram-se entre os valores de 0,5 e $4,0 \%$ descritos para $P$. scrofa, $P$. cearensis e $P$. nigricans (Maia et al., 1983 e Junk, 1985). O habitat tem pouca influência sobre o teor de proteína dos peixes do gênero Prochilodus, enquanto que a pequena variação de proteína observada nas fêmeas do estoque migrador I, talvez se deva a variação sazonal de alimentos. Sabe-se que tais espécies são iliófagas ou limnófagas, e, portanto se alimentam de lodo ou lama do fundo dos lagos contendo algas (especialmente diatomáceas), detritos vegetais e partículas de areia, provavelmente presente em maior quantidade e diversidade na época da chuva.

\section{CONCLUSÕES}

Tendo em vista a grande importância sob o ponto de vista zootécnico que a espécie Prochilodus lineatus representa, além de credenciá-la como espécie reconhecida no mercado nacional e internacional, conclui-se que os peixes machos pesando em média $591 \mathrm{~g}$, pertencentes ao estoque migrador I (capturados em dezembro), apresentaram melhores rendimentos de filé e os estoques migradores são peixes que

Tabela IV. Médias de proteína dos filés sem osso de curimbatá (Prochilodus lineatus) considerando os estoques e o sexo. (Protein averages of fillet boneless of curimbatá (Prochilodus lineatus) considering the supplies and the sex).

\begin{tabular}{lcccc}
\hline Estoques & Residente & \multicolumn{3}{c}{$\begin{array}{c}\text { Migrador } \\
\text { II }\end{array}$} \\
Sexo & & III \\
\cline { 2 - 5 } Macho & $19,08^{\mathrm{Aa}}$ & $18,41^{\mathrm{Aa}}$ & $19,91^{\mathrm{Aa}}$ & $18,22^{\mathrm{Aa}}$ \\
Fêmea & $18,27^{\mathrm{Aa}}$ & $10,90^{\mathrm{Bb}}$ & $19,41^{\mathrm{Aa}}$ & $19,30^{\mathrm{Aa}}$
\end{tabular}

Médias seguidas da mesma letra na coluna (maiúscula) e linha (minúscula), não diferem entre si pelo teste de Tukey $(p>0,05)$. 


\section{MACHADOEFORESTI}

tem baixo teor de gordura e alto teor de proteína e se enquadram entre os peixes magros e de alto valor nutricional. A comparação dos teores de proteína dos

\section{BIBLIOGRAFIA}

AOAC. 2000. Association of Official Analytical Chemists Official Methods of Analysis of AOAC International. $17^{\text {th }}$. v. II.

Carneiro, P., J.D. Mikos e F. Bendhack. 2003. Processamento: $O$ jundiá como matéria-prima. Panorama da Aquicultura, julho/agosto. p.17-21. Contreras-Guzmán, E.S. 1994. Bioquímica de pescado e derivados. Funep. Jaboticabal. 409 p.

Jacquot, R. 1961. Organic constituents of fish and foods. In: Fish and food. v. I. Ed. G. Borgsrom. New York. USA. p. 144-192.

Junk, W.J. 1985. Temporary fat storage an adaptation of some fish species to the waterlevel fluctuation and related environmental changes of the Amazon river. Amazoniana, 9: 315-351.

Macedo-Viegas, E.M. e C.M.D.F. Scorvo. 2000. Efeito das classes de peso sobre a composição corporal e o rendimento de processamento de matrinxã (Brycon cephalus). Acta Sci. Anim. Sci., 23: 725-728.

Maia, E.L., D.B. Rodriguez-Amaya and J. AmayaFarfán. 1983. Proximate, fatty acid and amino acid composition of the Brazilian freshwater fish Prochilodus scrofa. Food Chem., 12: 275286.

Ogawa, M. 1999. Características especificas do pescado. Em: Ogawa, M.; Maia, E.L. (Eds.). Manual de pesca ciência e tecnologia do pescado. Varela. São Paulo. p. 9-15.

Rasmussen, R.S. and T.H. Ostenfeld. 2000. Effect of growth rate on quality traits and feed utilization of rainbow trout (Oncorhyncus mykiss) and brook trout (Salvelinus fontinalis). Aquaculture, 184: 327-337.

Regost, C., J. Arzel, M. Cardinal, M. Laroche and estoques migradores e residentes do gênero Prochilodus sugerem que o habitat não interfere nos resultados da proteína, porém devem-se realizar mais estudos.

S.J. Kaushik. 2001. Fat deposition and flesh quality in seawater reared, triploid brown trout (Salmo trutta) as affected by dietary fat levels and starvation. Aquaculture, 193: 325-345.

SAS. 2001. Statistical Analyses System. SAS/ STAT. User's guide: statistics, version 8. CDROM. Cary.

Silva, J.J. and R.S. Chamul. 2000. Composition of marine and freshwater finfish and shellfish species and their products. In: R.E. Martin, E. Paine, E.J. Flick, L.M. Davis (Eds.). Marine and freshwater products handbook. Technomic Publishing Company, Inc. USA. p. 31-46.

Sivasundar, A., E. Bermingham and G. Orti. 2001. Populations structure and biogeography of migratory freshwater fishes (Prochilodus: Characiformes) in major South American rivers. Mol. Ecol., 10: 407-417.

Souza, M.L.R. 2001. Industrialização, comercialização e perspectivas. Fundamentos da moderna aqüicultura. Ed. ULBRA. Canoas. p. 149-189.

Souza, M.L.R., E.M. Macedo-Viegas e S.N. Kronka. 1999. Influência do método de filetagem e categorias de peso sobre o rendimento de carcaça, filé e pele de tilapia do Nilo (Oreochromis niloticus). Rev. Bras. Zootecn., 28: 1-6.

Stansby, M.E. 1954. Proximate composition of fish. In: Heen, E.; Kreuzer, R. (Eds.). Fish in Nutrition. Fishing News. London. p. 55-60.

Wille, K., E. McLean, J.S. Goddard and J.C. Byatt. 2002. Dietary lipid level and growth hormone alter growth and body conformation of blue tilapia Oreochromis aureus. Aqüaculture, 209: 219-232. 